\title{
CRENÇAS LINGUÍSTICAS DE ALUNOS DO ENSINO FUNDAMENTAL: UM ESTUDO SOCIOLINGUÍSTICO
}

\section{LINGUISTIC BELIEFS OF ELEMENTARY SCHOOL STUDENTS: A SOCIOLINGUISTIC \\ STUDY}

\begin{abstract}
BARBOSA, Juliana Bertucci
Professora Associada do Departamento de Linguística e Língua Portuguesa (DLLP) da Universidade Federal do Triângulo Mineiro (UFTM) e Professora Colaboradora do Programa de Linguística e Língua Portuguesa pela UNESP (FCLAr/Araraquara).

E-mail: julianabertucci@gmail.com

ORCID ID: http://orcid.org/0000-0002-1510-633X
\end{abstract}

\section{PELUCO, Larissa Campoi}

Doutoranda em Linguística e Língua Portuguesa pela UNESP (FCLAr/Araraquara).

E-mail: larissapeluco@gmail.com

ORCID ID: http://orcid.org/0000-0001-9721-8759

\section{GHESSI-ARROYO, Rafaela Regina}

Doutoranda em Estudos Linguísticos pela UNESP (IBILCE/São José do Rio Preto).

E-mail: rafaela.rghessi@gmail.com

ORCID ID: http://orcid.org/0000-0003-3816-111X

\section{RESUMO}

Este trabalho, pautado na abordagem teórico metodológica da Sociolinguística Variacionista (WEINREICH et al., 2006 [1968]; LABOV, 2008), tem como objetivo analisar crenças linguísticas de alunos do Ensino Fundamental de uma escola pública da cidade de Monte Azul Paulista, município do interior de São Paulo. Assumimos que as crenças dos alunos sobre a língua são construídas ao longo de seus anos de aprendizagem no contexto escolar, acrescidas, incontestavelmente, pelas experiências vivenciadas em seu contexto social. O trabalho dessa natureza no contexto escolar possibilita investigar a realidade linguística que perpassa o contexto escolar e discutir a importância de extinguir preconceitos linguísticos e conscientizar alunos (e professores) a respeito da heterogeneidade ordenada do sistema linguístico. Pelas respostas do teste de crenças linguísticas, verificamos a aproximação 
dos alunos às convenções e aos padrões institucionalizados: há imagens e significações sobre a língua que está dissociada de uma concepção de língua heterogênea, dinâmica, variável e social.

Palavras-chave: Crenças linguísticas. Ensino Fundamental. Sociolinguística.

\section{ABSTRACT}

This work, based on the theoretical methodological approach of Variationist Sociolinguistics (WEINREICH et al., 2006 [1968]; LABOV, 2008), aims to analyze linguistic beliefs of elementary school students from a public school in the city of Monte Azul Paulista, city in the state of São Paulo. We assume that students' beliefs about language are built over their years of learning in the school context, added, undoubtedly, by the experiences lived in their social context. The work of this nature in the school context makes it possible to investigate the linguistic reality that permeates the school context and discuss the importance, of extinguishing linguistic prejudices and making students (and teachers) aware of the ordered heterogeneity of the linguistic system. Through the responses of the test of linguistic beliefs, we verify the students approximation to the institutionalized conventions and standards: there are images and meanings about the language that are dissociated from a heterogeneous, dynamic, variable and social conception of language.

Keywords: Linguistic beliefs. Elementary school. Sociolinguistics.

\section{INTRODUÇÃO'}

Muitos trabalhos sociolinguísticos estão possibilitando um novo olhar no âmbito educacional, evidenciando a importância de se trabalhar com a heterogeneidade da língua. Essa concepção define que todas as línguas vivas, usadas para a comunicação, variam e mudam, de modo que toda variação e mudança não são aleatórias, mas sim estruturadas, organizadas e instruídas por diferentes fatores, estes que são não apenas linguísticos, mas também de ordem social. Bortoni-Ricardo (2005) dedicou-se a vários estudos e pesquisas a esse respeito. Em suas palavras:

A principal influência dos estudos sociolinguísticos para a educação provém da ênfase veemente na premissa de que

1 Agência de Fomento: CNPq e CAPES. 
todas as variedades que compõem a ecologia linguística de uma comunidade, sejam elas línguas distintas ou dialetos de uma ou mais de uma língua, são funcionalmente comparáveis e essencialmente equivalentes. Muito embora os preconceitos linguísticos não tenham desaparecido, a sociolinguística forneceu munição teórica e tecnológica para combatê-los, bem como para que os sistemas escolares começassem a se preocupar com a adequação de seus métodos às peculiaridades linguísticas e culturais de seus alunos que não provinham das camadas dominantes da sociedade (BORTONI- -RICARDO, 2005, p. 151).

Dessa forma, trabalhos que se preocupam com o ensino de língua portuguesa nas escolas observam a maneira como o professor e alunos pensam, avaliam as questões relacionadas à língua, à sociedade e as consequências de um ensino coercitivo na vida dos alunos. Tais estudos demonstraram que há um distanciamento entre as descobertas sociolinguísticas e o ensino de língua portuguesa nas escolas, no qual há a criação da ideia de que existe apenas um modo de falar e escrever corretamente e que a maneira como os alunos falam é errada e deve ser eliminada. De acordo com Faraco (2011, p.266), “[...] as pessoas se orientam por uma imagem segundo a qual há, na língua, princípios claros e indiscutíveis de correção. E por isso, acreditam que podem censurar com convicção e autoridade, ou com deboche e sarcasmo, o comportamento linguístico dos outros".

É pensando nesse importante papel da Sociolinguística no ensino que se faz necessários trabalhos que investigam o que os alunos pensam sobre a língua/linguagem, pois, assim, será possível observar a realidade linguística que perpassa o contexto escolar e discutir a importância de extinguir preconceitos linguísticos e conscientizar alunos (e professores) a respeito da heterogeneidade ordenada do sistema linguístico. Dessa forma, este trabalho tem como objetivo analisar crenças linguísticas de alunos do Ensino Fundamental de uma escola pública da cidade de Monte Azul Paulista, município do interior de São Paulo. Assume-se, neste trabalho, que as crenças dos alunos sobre a língua são construídas ao longo de seus anos de aprendizagem no contexto escolar, acrescidas, incontestavelmente, pelas experiências vivenciadas em seu contexto social. O trabalho dessa natureza no contexto escolar tem como um dos desafios a reconstrução do imaginário sobre a língua. Como afirma Santos (1996, p. 15), "Várias pesquisas produziram evidências de que 
a atitude de um indivíduo pode ser mudada, se forem mudadas suas crenças sobre o objeto".

Primeiro discutiremos os conceitos de crenças linguísticas, suas características e importância na área educacional. Após isso apresentamos trabalhos sobre crenças linguísticas no contexto escolar. Por fim, exporemos a metodologia e os resultados obtidos através dos formulários preenchidos pelos alunos.

\section{CRENÇAS LINGUÍSTICAS}

Muitas áreas do conhecimento se valem das crenças no desenvolvimento de trabalhos, como a Filosofia, História, Sociologia, Sociolinguística dentre outras. Desse modo, definir o que sejam "crenças" não é tarefa fácil, pois cada área possui um objeto de estudo, rendendo então, muitas definições para o termo. Barcelos (2004) sobre a natureza do que seriam crenças:

[...] não são somente um conceito cognitivo, mas também social, porque nascem de nossas experiências e problemas, de nossa interação com o contexto e da nossa capacidade de refletir e pensar sobre o que nos cerca. (BARCELOS, 2004, p. 132).

Outros autores reforçam a dificuldade em se conceituar "crenças", como Pajares (1992), que apresenta termos referidos a elas como: atitudes, valores, ideologia, percepções, etc. Isso deixa clara a complexidade na definição do termo. De modo geral, crenças podem ser definidas como opiniões ou ideias que as pessoas possuem sobre algo.

Barcelos (2007) afirma que crença é algo muito antigo, tão antigo quanto nossa existência, pois desde que o homem começou a pensar, ele passou a acreditar em algo. A mesma autora acredita que as crenças são dinâmicas, sociais e não estáticas como por muito tempo se pensou. Isso não significa que elas mudam de uma hora pra outra, mas que elas mudam ao longo do tempo, baseado em pessoas que os falantes julguem importantes, fatos do passado da vida do informante. As crenças nascem das interações sociais e apresentam um paradoxo, pois ao mesmo tempo em que são sociais, elas são também individuais, atingem cada indivíduo de maneira única.

Dessa forma, as crenças influenciam no comportamento dos indivíduos. No ensino, elas podem influenciar na motivação e busca por estratégias de aprendizagem tanto do professor como dos alunos. 
Nesses casos, vemos a crença ligada à emoção. Quando a crença de alguém é questionada, ou algo que o indivíduo acredita é posto em dúvida, normalmente a pessoa reage imediatamente. Se o aluno acredita que não consegue aprender tal conteúdo, que o português é difícil, estudar gramática é algo distante da sua realidade, isso induzirá a um comportamento consoante às suas crenças. E mudar as crenças que possuem para mudar a relação com o processo de aprendizagem não é algo simples.

Então, apesar de dinâmicas, as crenças podem resultar num bloqueio para as mudanças. De acordo com Barcelos (2007), elas se ancoram em algo e não são geradas imediatamente. E por que seria tão difícil mudar? Justamente pela natureza das crenças, que apresentam uma estrutura complexa segundo o modelo de Rokeach (1968) apud Barcelos (2007).

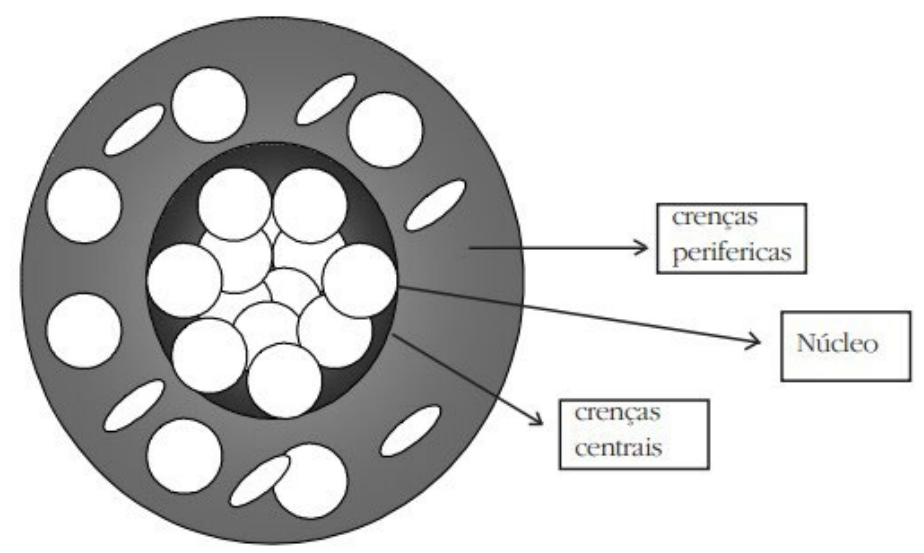

2. Crenças Centrais

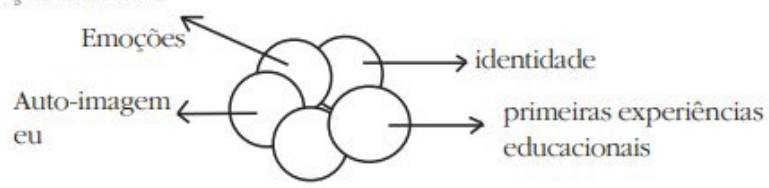

Figura 1: Representação da estrutura das crenças como crenças centrais e periféricas

Fonte: Barcelos (2007, p. 118)

Nesse modelo, Rokeach (1968 apud BARCELOS 2007) afirma que as crenças são agrupadas em crenças centrais e crenças periféricas. As centrais seriam mais resistentes à mudança. Dewey (1933) chamou 
essas crenças mais centrais de "crenças de estimação", porque seriam as crenças às quais existe mais apego e que não são desapegadas facilmente. Essas crenças centrais ainda estariam ligadas à emoção e a identidade.

Então, como essas crenças são centrais, elas se relacionam com as outras crenças existentes ao redor. Mudar uma crença central implicaria mudar todo o sistema. Para que um indivíduo conseguisse uma mudança, ele precisaria desconstruir algumas crenças existentes e assim permitiria que novas fossem incorporadas.

Pajares (1992) salienta que para que uma crença mude efetivamente, uma pessoa precisaria percebê-la como não satisfatória, o que aconteceria quando essa crença seria desafiada ou não seria mais possível apropriar-se de novas crenças em seu sistema estrutural de crenças. Se essa crença não se mostrar eficiente, corre também o risco de ser eliminada.

No ensino, as crenças possuem extrema importância. Como dito anteriormente, elas podem bloquear uma mudança ou até mesmo criar um entrave para a aprendizagem. Por outro lado, as crenças podem influenciar na motivação, nas atitudes, estratégias usadas tanto pelos alunos como pelos professores.

Como exemplo de crenças bloqueadoras citamos Bagno (2002), que mostra crenças comuns sobre o português como: "brasileiro não sabe português", "só em Portugal se fala bem o português", "português é bem difícil". Essas crenças, tão comuns, acabam por fazer os indivíduos reagirem negativamente frente à língua materna e a acreditar que sua própria língua não lhes pertence, como algo distante de sua realidade, uma baixa autoestima linguística. Muitas vezes, o descaso com a educação, falta de políticas públicas que contemplem aluno e professor, que valorizem os profissionais desse meio, acabam por criar crenças difíceis de desconstruir e que afetam diretamente a atuação de todos os membros da escola.

Para que se consiga alterar esse cenário tão habitual, é preciso ações de conscientização de usos linguísticos reais e não apenas pautados na tradição gramatical, um amadurecimento a respeito do preconceito linguístico, mais do que isso, uma busca pelo respeito linguístico, respeito pelo conhecimento intuitivo do aluno. É desafiando as crenças antigas e profundamente arraigadas que haverá chances de um ensino democrático, real e motivador e inclusivo. 


\section{PESQUISAS SOBRE CRENÇAS LINGUÍSTICAS NO CONTEXTO ESCOLAR}

Os estudos sobre Crenças Linguísticas na perspectiva da Sociolinguística Variacionista (WEINREICH et al., 2006 [1968]; LABOV, 2008 [1972]), têm contribuído muito para a compreensão dos processos de variação linguística e para a reflexão sobre o processo de ensinoaprendizagem guiado pela questão da diversidade linguística. Assim, pesquisas sobre Crenças podem ampliar a discussão sobre fatores de mudanças linguísticas, sobre a necessidade de um ensino sem danos aos valores sociais dos alunos, bem como sobre questões de prestígio e desprestígio - que levam ao preconceito linguístico não só em relação à língua que o outro fala, mas também em relação à comunidade desses falantes.

Silva e Botassini (2015), defendendo um ensino de língua portuguesa que privilegie o aprimoramento da língua materna, a história, o sujeito e o contexto, buscaram verificar quais são as crenças de alunos de Letras quanto ao processo de ensino/aprendizagem da língua materna na escola. Para as autoras, ter como o foco de estudo alunos da graduação é importante para entender sobre o panorama a ser superado no processo de formação de professores, uma vez que são eles que estarão a frente de outros indivíduos discursando sobre língua e construindo representações. As autoras demonstraram que as crenças dos informantes são predominantemente negativas em relação ao ensino de língua portuguesa na escola, em virtude, sobretudo, do despreparo dos professores, de alguns problemas de currículo e da falta de conhecimento prévio dos alunos (SILVA e BOTASSINI, 2015, p. 61). De acordo com Silva e Botassini (2015):

Um número significativo de informantes acredita que saber português está relacionado a ter domínio/conhecimento das regras gramaticais. Esse resultado aponta que, embora os falantes, em sua maioria, tenham relatado que tiveram contato com a Sociolinguística e com estudos variacionistas, suas crenças ainda são fortemente marcadas pelo ensino de língua portuguesa voltado para a normatização (certo versus errado). Tais crenças, de certa forma, contribuem para reforçar a prática de um ensino de língua portuguesa voltado para o estudo da gramática normativa. (SILVA; BOTASSINI, 2015, p. 61). 
A escola, que prioriza o ensino da língua materna com foco na gramática normativa, acaba sendo um ambiente propício para a distorção da realidade linguística e propagação de preconceitos linguísticos, silenciando sujeitos externos a uma norma idealizada, que é carregada de ideologias e de relações de poder (PETERMANN e ALVES, 2018). Dessa forma, os professores, que deviam ser agentes que descontroem estereótipos linguísticos, hesitam em se trabalhar a pluralidade da língua dentro de sala de aula, tornando cristalizada a metodologia conservadora e excludente e relegando a segundo plano a variação linguística (GHESSI, 2020).

Cyranka (2007), por sua vez, investigou a avaliação de alunos da oitava série do Ensino Fundamental de escolas públicas de Juiz de Fora-MG em relação a três variedades linguísticas: a rural, a rurbana e a urbana. A autora também analisou a correlação existente entre as crenças dos professores e as crenças e atitudes desses alunos com o objetivo de observar a intervenção no desenvolvimento, no aluno, de competências comunicativas ${ }^{2}$ de uso da variedade culta $^{3}$. Os resultados evidenciaram que os alunos estão em enfrentamento entre a valorização de sua variedade linguística (observado nos testes de atitudes linguísticas) e a afirmação de que não sabem escrever, nem falar bem (observado nos testes de crenças linguísticas). Nas palavras de Cyranka (2007):

Creio que esta pesquisa, tendo focalizado o aluno, suas atitudes subjetivas e crenças, conseguiu evidenciar, empiricamente, o que é uma suposição bastante comum: a escola falha, quando insiste em desconhecer o que é próprio do aluno, sua cultura, sua vivência, sua linguagem. A simples imposição de uma variedade linguística, com a justificativa de que é a mais prestigiada não é suficiente para fazê-lo aderir a ela. Nesse caso, não há diferença, pelo menos no estágio atual da crise de ensino no Brasil, entre alunos de qualquer procedência. (CYRANKA, 2007, p.129-130).

Barbosa e Cuba (2015), na cidade de Uberaba-MG, realizaram um estudo sobre atitudes e crenças linguísticas de alunos do Ensino

2 Entendemos que a competência comunicativa inclui "[...] não só as regras que presidem à formação das sentenças, mas também as normas sociais e culturais que definem a adequação da fala" às diferentes situações de comunicação (BORTONI-RICARDO, 2004, p. 73).

3 Faraco (2008) propõe um tratamento para a polissemia que envolve a concepção de norma. Norma culta/ comum/standard é a "variedade que os letrados usam correntemente em suas práticas mais monitoradas de fala e escrita" (FARACO, 2008, p. 73), enquanto norma-padrão é uma "codificação relativamente abstrata, uma baliza extraída do uso real para servir de referência, em sociedades marcadas por acentuada dialetação, a projetos políticos de uniformização linguística" 
Médio em escolas públicas da cidade. De maneira geral, os resultados mostraram que os alunos: (i) acreditam que a língua escrita é mais correta que a falada e que, dessa forma, escrevem melhor do que falam; (ii) pensam que uma das funções da escola é corrigir a fala dos alunos; (iii) pensam que os adultos falam melhor que os jovens; (iv) consideram a linguagem dos livros mais bonita e melhor do que seu próprio "jeito de falar"; (v) acreditam que falar bem é tão importante quanto escrever bem; (vi) demonstraram que um professor de Português competente deve falar de acordo com as regras da gramática; (vii) acreditam que seu professor de Português fala corretamente e, por fim, (viii) afirmaram que mudam sua maneira de falar de acordo com a situação em que estão.

Tais resultados apresentados foram semelhantes aos resultados da pesquisa recente de Ghessi (2020), na qual os alunos também demonstraram pensar que há maneiras de falar "mais bonitas" do que a deles e demonstram preconceito linguístico em relação à própria fala e a de outras variedades. Ghessi (2020), ao analisar atitudes linguísticas de alunos do Ensino Médio de duas escolas públicas da cidade de Monte Azul Paulista-SP, observou que há imagens e significações que recobrem a língua e são reforçados por todas as instâncias da sociedade, inclusive pela escola. Ao perguntarem aos alunos se eles gostam de Língua Portuguesa, observou que acreditam que a Língua Portuguesa se limita a regras e nomenclaturas e que qualquer uso linguístico que desvie dessas regras deve ser eliminado, pois não é o uso "correto" e nem o mais "bonito". Além disso, as respostas evidenciaram que os alunos sentem dificuldade com a disciplina na escola, uma vez que é baseada em "regras", e não guiada por uma pedagogia inovadora, que possibilita a reflexão gramatical e que amplie as competências linguísticas dos alunos. De acordo com Ghessi (2020):

A disciplina de Língua Portuguesa não pode ser vista como uma problemática, pois a língua é um bem identitário e cultural, que faz parte de todas as nossas práticas sociais [...] O interesse deve vir pela busca de recursos comunicativos que lhes permitem desempenhar-se competentemente em práticas sociais especializadas. Ou seja, os alunos precisam ter um objetivo real para gostarem de ir às aulas de Língua Portuguesa e isso só acontecerá se o ensino for voltado ao respeito às diferenças (GHESSI, 2020, p. 90).

A partir do exposto, verificamos, portanto, que há uma crença social sobre a língua e o que "é ensinar Língua Portuguesa" presente em 
inúmeras instâncias da sociedade, sobretudo na escola. Com estudos que abordam sobre crenças linguísticas será possível estimular uma nova prática pedagógica pautada na reflexão sobre a heterogeneidade do sistema linguístico, pois, assim, os professores poderão desconstruir crenças dos alunos perante a língua materna, crenças essas que são tão fortes em nossa sociedade. Temos um caminho longo e árduo pela frente, pois as crenças são orientadas por um viés ideológico elitista e conservador que contribui para a reprodução de preconceitos linguísticos. Como afirma Milroy (2011, p.62): "Não se trata de estrutura linguística, tal como os linguistas a entendem: trata-se de ideologia, e se os linguistas afirmarem que todas as variedades são "gramaticais" (o que elas, é claro, são), suas opiniões serão interpretadas como ideológicas, não linguísticas".

\section{PROCEDIMENTOS METODOLÓGICOS}

Primeiramente foi realizada uma revisão bibliográfica sobre os conceitos de Crenças Linguísticas, refletindo seu impacto no ensino/ aprendizagem de língua portuguesa. Em seguida, partindo de estudos da área da Sociolinguística, foram aplicados a alunos do Ensino Fundamental ${ }^{4}$ de uma escola da rede pública de Monte Azul Paulista-SP um teste de crenças linguísticas ${ }^{5}$, com 9 questões diretas, em que tinham que julgar as assertivas como verdadeira ou falsa, como podemos ver a seguir:

\begin{tabular}{|l|l|l|}
\hline \multicolumn{1}{|c|}{ Afirmações } & V & F \\
\hline A língua ESCRITA é mais correta do que a FALADA. & & \\
\hline Para ESCREVER bem, basta conhecer as regras de ortografia. & & \\
\hline Para ESCREVER direito, deve-se melhorar o jeito de FALAR. & & \\
\hline A língua dos livros é sempre melhor e mais bonita do que o meu modo de FALAR. & & \\
\hline As pessoas analfabetas FALAM errado. & & \\
\hline A língua ESCRITA é mais complicada que a língua FALADA & & \\
\hline $\begin{array}{l}\text { O meu jeito de falar é igual ao das pessoas com quem convivo, por isso eu tenho } \\
\text { orgulho do meu jeito de falar. }\end{array}$ & & \\
\hline Em qualquer situação da vida, posso FALAR do mesmo jeito. & & \\
\hline Há outras FALAS mais bonitas que a do Interior de SP, como a de: & \\
\hline
\end{tabular}

Quadro 1: Teste de crenças linguísticas

Fonte: adaptado de Cyranka (2007)

4 Aprovado pelo Comitê de Ética (Protocolo 94124918.8.0000.5400) da Universidade Estadual Paulista "Júlio de Mesquita Filho" (Campus de Araraquara-SP).

5 Adaptado de Cyranka (2007). 
Os alunos selecionados para participarem da pesquisa estudam no $9^{\circ}$ ano, possuem cinco aulas semanais de Língua Portuguesa. A escola pública frequentada por eles localiza-se distante do centro e atende alunos de diversos bairros da cidade, inclusive os que habitam os sítios das redondezas. De forma geral, a renda das famílias não é maior que dois salários mínimos. No $9^{\circ}$ ano, os alunos já percorreram quase a totalidade do conteúdo programático, incluindo reflexões sobre a língua materna, mas isso não os impedem, como será visto nas próximas seções, que possuam crenças que reforcem a concepção de língua homogênea, pois, a concepção social de padronização da língua reflete-se no ensino de Língua Portuguesa nas escolas brasileiras e nos livros didáticos adotados pelos professores que, embora apresentem variação linguística como conteúdo, aparentemente não adotam a concepção de língua como prática social em suas abordagens em sala de aula ${ }^{6}$.

\section{ANÁLISE DOS DADOS}

Nesta seção, serão apresentados os resultados obtidos por meio das respostas dos questionários aplicados aos alunos do Ensino Fundamental. A primeira questão que os alunos tinham que julgar como verdadeira ou falsa era a seguinte: A língua ESCRITA é mais correta do que a FALADA.

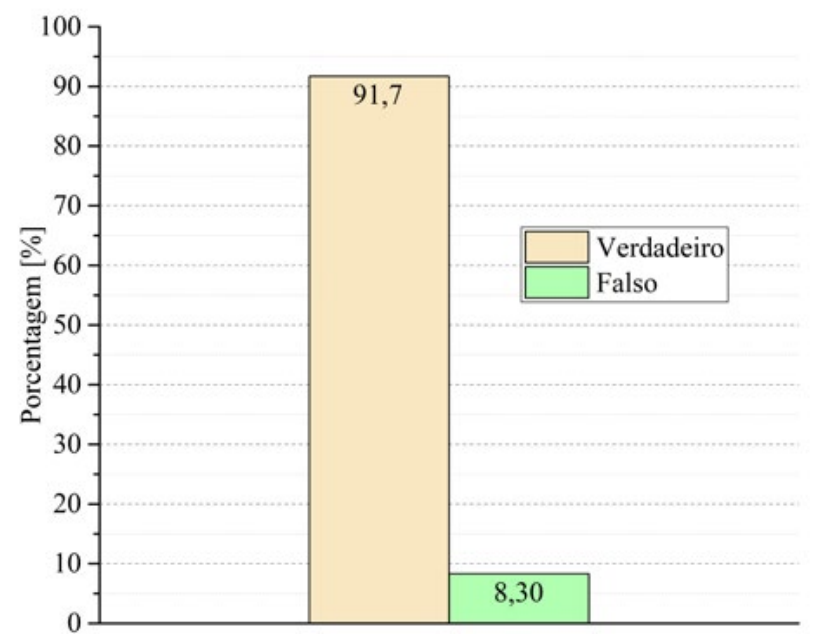

Figura 2: Resultado das respostas sobre a assertiva "A língua ESCRITA é mais correta do que a FALADA".

Fonte: própria das autoras.

6 Petermann e Alves (2018) analisaram três livros didáticos com o objetivo de observar a forma como abordam a variação linguística. Suas análises evidenciaram que, de alguma maneira, os livros estavam ligados à Ideologia da Padronização (MILROY, 2011), pois parecem conceber a língua como um sistema único e fechado que é exterior ao falante. Para os autores, a abordagem de ensino desses livros visa mais "ao reconhecimento e classificação das "variedades" do que a reflexão acerca da existência e da persistência dos fenômenos linguísticos" e enxergam a variação linguística como "distorções de um padrão ilusório da língua" (PETERMANN e ALVES, 2018, p. 19). 
Diante dessa afirmação, apenas 8,3 \% considerou falsa. Para tal reflexão, tem-se que pontuar a importância da relação entre língua escrita e língua falada. No âmbito dos estudos linguísticos, as reflexões sobre fala e escrita abrangem diferentes perspectivas (MARCUSCHI, 2000). A primeira delas é a que se dedica à análise das duas modalidades de uso da língua de forma dicotômica. Essa perspectiva, que foi adotada pela maioria das gramáticas pedagógicas, deu origem ao prescritivismo de uma única norma linguística, que divide a língua falada e a língua escrita em dois blocos distintos, como podemos observar a seguir:

\begin{tabular}{|c|c|}
\hline Fala & Escrita \\
\hline Contextualizada & Descontextualizada \\
\hline Dependente & Autônoma \\
\hline Implícita & Explícita \\
\hline Redundante & Condensada \\
\hline Não-planejada & Planejada \\
\hline Imprecisa & Precisa \\
\hline Não-normatizada & Normatizada \\
\hline Fragmentária & Completa \\
\hline
\end{tabular}

Quadro 2: Diferença entre fala e escrita de um ponto de vista dicotômico.

Fonte: Marcuschi (2000, p. 27).

Marcuschi (2000) atenta para o fato de que não se deve analisar escrita x fala numa perspectiva dicotômica, ou seja, relacionar à escrita o planejamento, pensamento, organização e com a fala relacionar implicitude, falta de organização. Quando abordada sob essa perspectiva, o aluno tende a relacionar escrita à formalidade e fala com informalidade, o que é extremamente incorreto. Há textos falados formais, como palestras e conferências e textos escritos informais, como cartas familiares, textos em Whatsapp, etc.

A crença de que a língua falada ou oral é inferior à escrita encontrase arraigada nesses e em muitos outros alunos, Brasil afora. Na escola, cabe ensinar e aprender a língua em seu funcionamento, como meio de interação, todas as modalidades como legítimos usos da língua, nenhuma forma mais correta que outra. Em relação à segunda assertiva- Para saber ESCREVER bem, basta conhecer as regras de ortografia- obtivemos os seguintes resultados: 


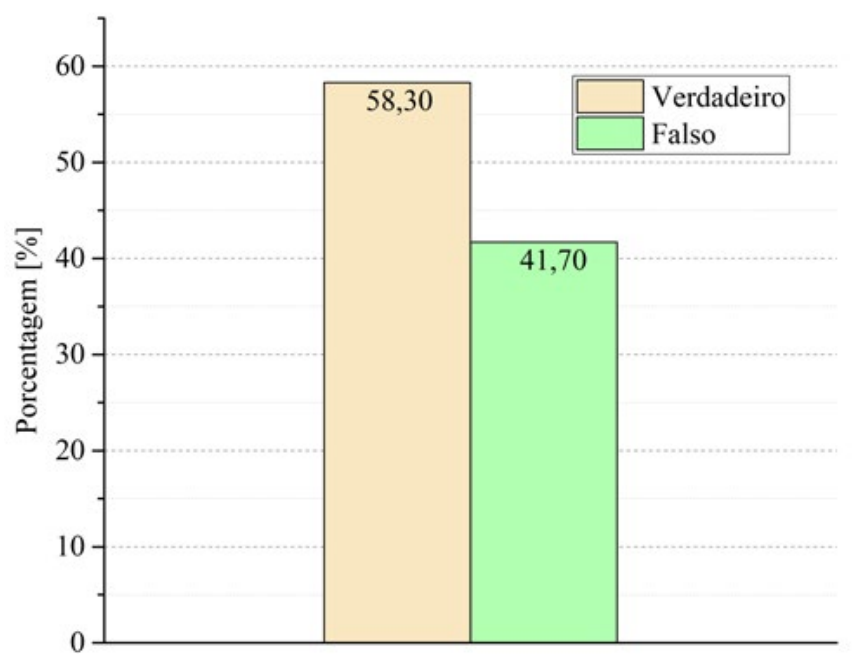

Figura 3: Resultado das respostas sobre a assertiva "Para saber ESCREVER bem, basta conhecer as regras de ortografia".

Fonte: própria das autoras.

Os alunos ficaram divididos diante dessa afirmação. 58,3\% dos alunos a colocaram como verdadeiro enquanto que $41,7 \%$ a avaliaram como falsa. Como refletido na assertiva anterior, a escrita e a fala vêm sendo ensinadas de forma dicotômica, uma excluindo o uso da outra, o que acaba por fazer os alunos depreenderem a escrita como superior. Já que a escrita encontra-se em tão alto patamar para as crenças desses 58,3\% alunos, nada mais que, para atingi-lo, saber as regras de ortografia torna-se peça fundamental para escrever bem. A escrita é a forma da organização, do planejamento e fazer isso sem uma boa ortografia não lhes garantiria sucesso. O status da escrita vem de uma tradição gramatical e sua forma encontra-se perpetuada em dicionários e gramáticas.

Para $41,7 \%$ alunos, no entanto, as regras de ortografia não são garantia de uma boa escrita. A escrita também está vinculada às ideias, não somente à ortografia. Sem boas ideias não há chances de escrever bem. E as ideias são estimuladas com a interação, leituras, mostrando claramente a relação intrínseca entre fala e escrita.

Em relação à terceira assertiva- Para ESCREVER direito, deve-se melhorar o jeito de FALAR- obtivemos os seguintes resultados: 


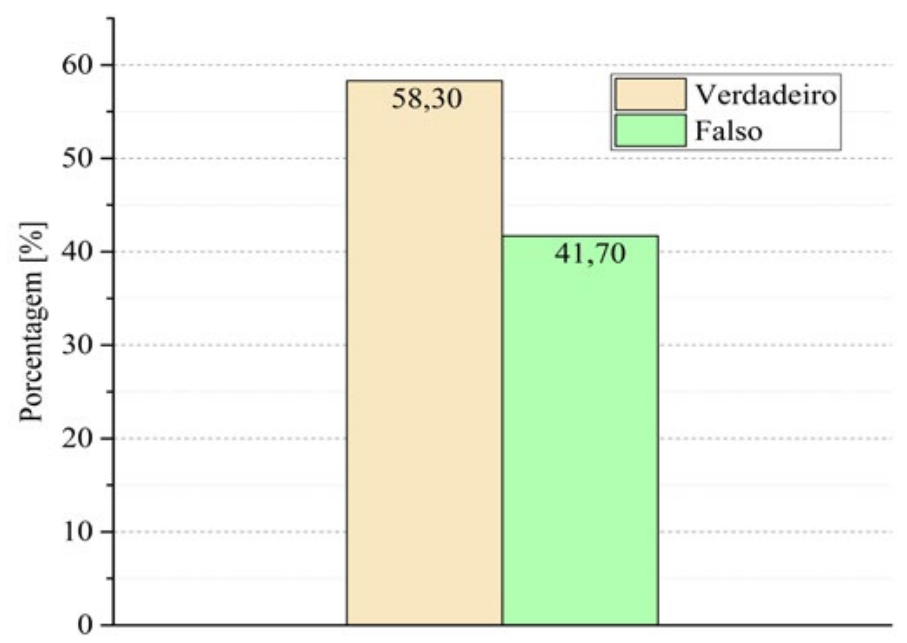

Figura 3: Resultado das respostas sobre a assertiva "Para ESCREVER direito, deve-se melhorar o jeito de FALAR".

Fonte: própria das autoras.

Na Figura 4, observa-se que 58,3\% alunos acreditam que para escrever direito é preciso melhorar o jeito de falar e 41,7\% acreditam que para escrever bem não implica melhorar o jeito de falar. Mais uma vez, a maioria dos alunos supervaloriza a língua escrita e mantém desprezo pela língua falada. Marcuschi (1998) afirma:

[...] como deve ser tratada a oralidade no ensino de língua. Uma atividade importante é sensibilizar o aluno para a sua própria fala a fim de fazer ver que ele já sabe muito de sua língua e deve aproveitar ao máximo esse conhecimento quando se expressar na escrita. De início, sabemos que a fala vai influenciar a escrita, mas depois ocorrerá inevitavelmente o contrário. (MARCUSCHI, 1998, p.144).

Supervalorizar a língua escrita e manter o desprezo pela língua falada impede o reconhecimento de uma verdadeira realidade linguística em nosso país. O ensino deveria ser pautado no letramento dos alunos, no ler e escrever eficientemente, permitindo que esse aluno transite por qualquer situação comunicativa, e não decorar nomenclaturas da gramática normativa. A desvalorização da fala, achar que tem que melhorá-la implica na manutenção do preconceito linguístico, esse por sua vez evidencia o abismo social presente na sociedade. A seguir exporemos os resultados da quarta afirmação: A linguagem dos livros é sempre melhor e mais bonita do que o meu modo de FALAR. 


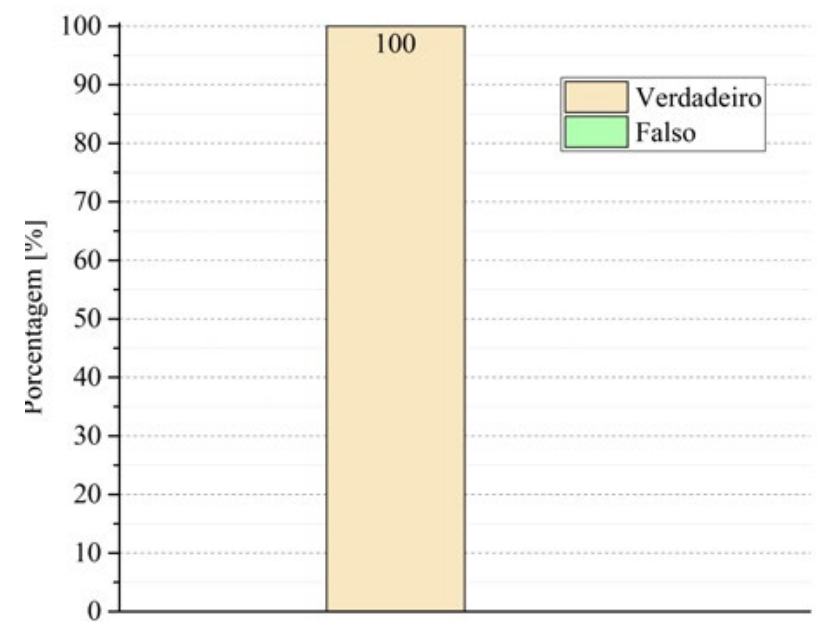

Figura 5: Resultado das respostas sobre a assertiva "A língua dos livros é sempre melhor e mais bonita do que o meu modo de FALAR".

Fonte: própria das autoras.

Diante dessa assertiva a resposta foi unânime: todos os alunos a consideraram verdadeira. Como a crença de que a escrita é superior à fala está profundamente arraigada, natural encontrar a crença de que a linguagem dos livros seja mais valorizada que o modo de falar. Afinal, há o culto aos escritores clássicos, com as frases extraídas de suas obras figurando como verdadeiros exemplos do "bom uso da língua". Desconsidera-se o uso real e vivo da língua, que ela é dinâmica, heterogênea e que muito mudou desde que os clássicos foram escritos.

Olhar apenas para o passado exclui grande parcela da população que não possui acesso à educação básica, aos livros cheios de exemplos da norma-padrão, mas que se comunicam eficientemente apesar disso. Crer que os livros têm um modo melhor de dizer algo que o seu modo de falar descaracteriza o que as pessoas têm de mais valioso: sua forma autêntica de comunicação. Ensinar que não existe um modo melhor de falar, ou uma língua melhor, mais correta mostra-se um caminho para uma verdadeira política linguística (BAGNO, 2015).

Na figura 6, a seguir, expomos os resultados para a quinta afirmativa do questionário: As pessoas analfabetas FALAM errado. 


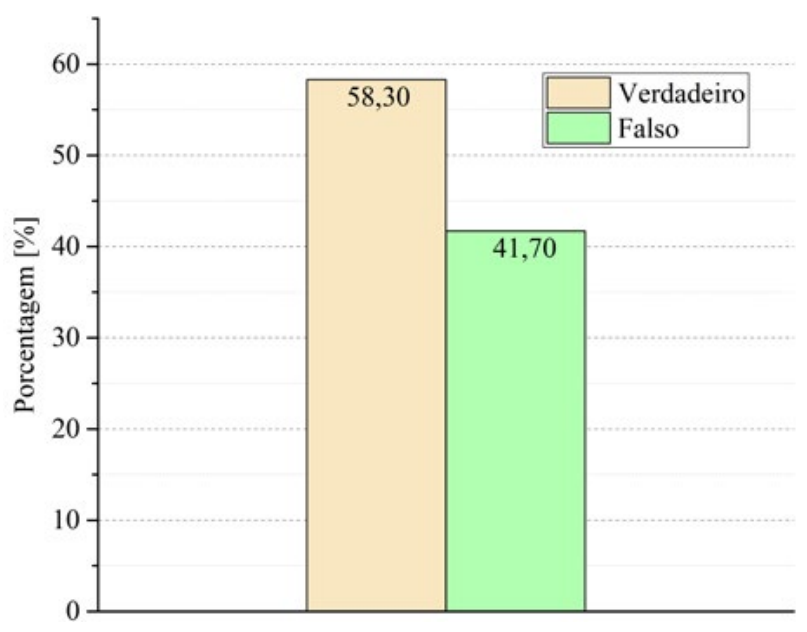

Figura 6: Resultado das respostas sobre a assertiva "As pessoas analfabetas FALAM errado".

Fonte: própria das autoras.

Ao observarmos o gráfico, podemos notar que, por um lado, é preocupante que os alunos do Ensino Fundamental acreditam que as pessoas analfabetas falam errado, por outro lado, também temos uma boa porcentagem de alunos que não compartilham da mesma crença. Nessa assertiva, podemos mencionar dois aspectos já discutidos anteriormente: (i) a noção de FALA e ESCRITA e (ii) a noção de CERTO e ERRADO.

No mundo moderno, a modalidade escrita tornou-se um bem sociocultural indispensável, adquirindo um valor social até superior à oralidade, uma vez que passou a simbolizar educação, desenvolvimento e poder. Nas palavras de Marcuschi (2000):

A fala (enquanto manifestação da prática oral) é adquirida naturalmente em contextos informais do dia-a-dia e nas relações sociais e dialógicas que se instauram desde o momento em que a mãe dá seu primeiro sorriso ao bebê. Mais do que decorrência de uma disposição biogenética, o aprendizado e o uso de uma língua natural é uma forma de inserção cultural e de socialização. Por outro lado, a escrita (enquanto manifestação formal do letramento), em sua faceta institucional, é adquirida em contextos formais: na escola. Daí também seu caráter mais prestigioso como bem cultural desejável (MARCUSCHI, 2000, p. 18). 
Pessoas analfabetas são aquelas que não possuem práticas de letramento escolar e não sabem ler e escrever. Assim, é normal associar a fala dessas pessoas como "errada". Isso significa que a linguagem da classe mais baixa, dos não escolarizados, é estigmatizada, levando ao preconceito, não apenas em relação à língua, mas também à comunidade linguística desses falantes. Daí a reflexão de Gnerre (1985, p.6), "[...] uma variedade linguística 'vale' o que 'valem' na sociedade os seus falantes, isto é, vale como reflexo do poder e da autoridade que eles têm nas relações econômicas e sociais". Frequentemente, tudo o que foge dos padrões estabelecidos é visto como "errado" e rejeitado pela sociedade ou pelos que se acham detentores da norma de prestígio. Logo, os indivíduos e, consequentemente, sua fala ou escrita, são alvos de atitudes e avaliações subjetivas negativas ocasionadas por repressões sociais (GHESSI, 2020, p. 105).

$\mathrm{Na}$ assertiva A língua ESCRITA é mais complicada que a língua FALADA reunimos, mais uma vez, a discussão sobre a dicotomia entre FALA x ESCRITA. Como vemos no gráfico abaixo, os alunos acreditam nessa declaração.

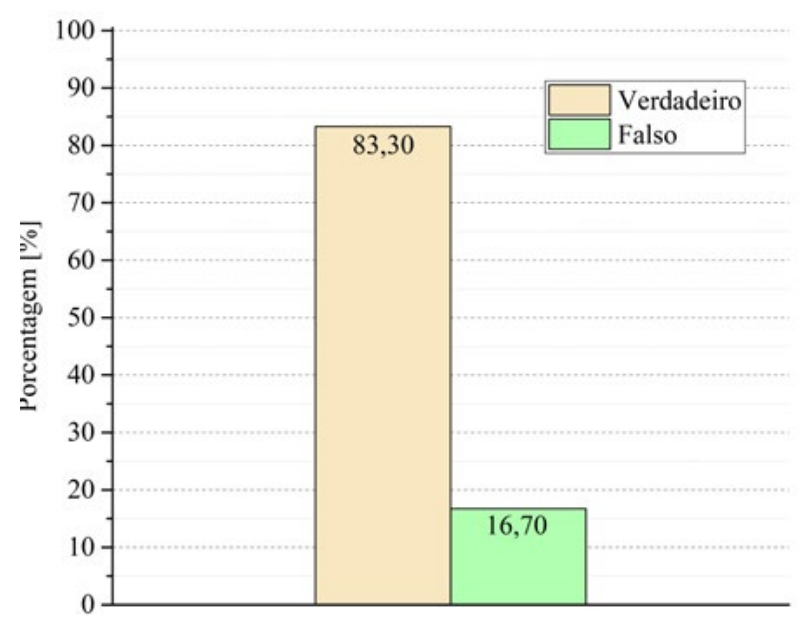

Figura 7: Resultado das respostas sobre a assertiva "A língua ESCRITA é mais complicada que a língua FALADA".

Fonte: própria das autoras.

Ao observarmos o Quadro 2, anteriormente explicitado, verificamos que a concepção evidenciada postula para a fala uma menor complexidade, um caos gramatical; enquanto que para a escrita postula uma maior complexidade, o lugar da norma, das regras e do bom 
uso da língua. Além disso, não há preocupação alguma com os usos discursivos nem com a produção textual. Marcuschi (2000) considera tal visão reducionista, uma vez que não analisa as diferenças entre fala e escrita por meio do uso, mas do sistema. Assim, essa noção, que impera no ensino de língua portuguesa nas escolas, reforça crenças de que a modalidade escrita é mais difícil que a modalidade falada.

Das discussões abordadas anteriormente, enfocamos, principalmente, nas crenças linguísticas sobre FALA x ESCRITA, CERTO $x$ ERRADO. $\mathrm{Na}$ assertiva $\mathbf{O}$ meu jeito de falar é igual ao das pessoas com quem convivo, por isso eu tenho orgulho do meu jeito de falar, que vamos analisar agora, discutiremos a noção de Prestígio Encoberto (LABOV, 2008 [1972]), denominado como um status particular atribuído pelos falantes de um determinado grupo social à sua própria variedade linguística ou vernáculo básico (BORTONI-RICARDO, 2005, p.49). De acordo com Chambers (1995), esse prestígio configura um caso de "contrapressão" a favor de uma variedade à qual se atribuem valores positivos. Isso significa que determinadas formas de linguagem se investem de um "status" particular, embora sejam desprovidas de prestígio na comunidade linguística em geral (PAIVA, 2003, p.40 apud CYRANKA, 2007, p.57). O gráfico a seguir demonstra que metade dos alunos participantes da pesquisa possui orgulho de sua forma de falar e de sua comunidade.

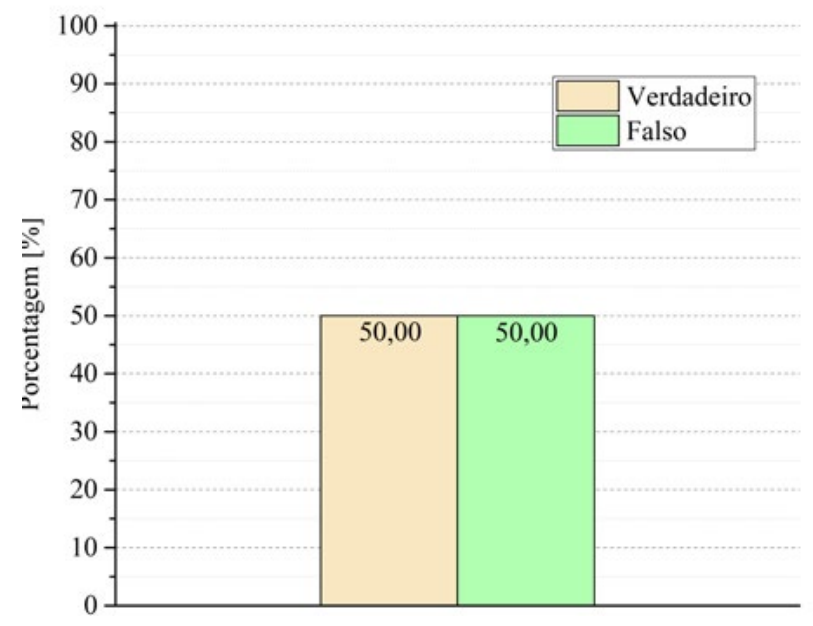

Figura 8: Resultado das respostas sobre a assertiva "O meu jeito de falar é igual ao das pessoas com quem convivo, por isso eu tenho orgulho do meu jeito de falar".

Fonte: própria das autoras. 
Depreende-se, portanto, que há nesses alunos um sentimento de solidariedade e pertencimento: com a inserção na instituição de ensino, os alunos começaram a possuir contato maior com a norma de prestígio, contudo, isso não fez com que perdessem a identidade do grupo.

Por último, apresentamos os resultados da assertiva: Em qualquer situação da vida, posso FALAR do mesmo jeito.

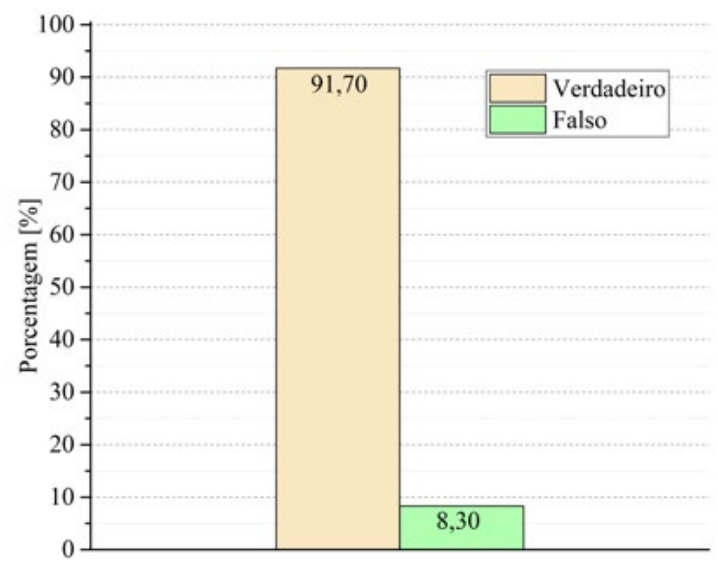

Figura 9: Resultado das respostas sobre a assertiva "Em qualquer situação da vida, posso FALAR do mesmo jeito".

Fonte: própria das autoras.

Como podemos observar, 91,7\% dos alunos julgaram falsa a assertiva, demonstrando que, apesar de terem em seu imaginário crenças que reforçam a homogeneidade e padronização linguística, possuem a conscientização da adequação linguística a determinados contextos de comunicação. Isso é muito positivo, pois inferimos que os professores de língua portuguesa desses alunos estão ampliando os conhecimentos com que os alunos chegam à escola. De acordo com Camacho (2003):

As variedades são alternativas e podem conviver harmoniosamente na sala de aula, cabendo ao professor o bom senso de discriminá-las adequadamente, fornecendo ao aluno as chaves para perceber as diferenças de valor social entre elas e, depois, saber tirar vantagem dessa habilidade, selecionando a mais adequada conforme as exigências das circunstâncias do intercurso verbal (CAMACHO, 2003, p.72). 
Uma pedagogia amparada à variação linguística considera as diferenças linguísticas presentes no contexto escolar e as utiliza para a conscientização e adequação a diferentes situações comunicativas, sem prejuízos no processo de ensino/aprendizagem. Os Parâmetros Curriculares Nacionais (PCNs) de língua portuguesa, assim como a Base Nacional Comum Curricular (BNCC), conceituam a língua como uma atividade sociointeracional e histórica, dando ênfase, portanto, ao ensino voltado para o uso, para a interação e para a diversidade linguística, fazendo referência à adequação ao contexto de comunicação.

[...] a questão não é falar certo ou errado, mas saber qual forma de fala utilizar, considerando as características do contexto de comunicação, ou seja, saber adequar o registro às diferentes situações comunicativas. É saber coordenar satisfatoriamente o que falar e como fazê-lo, considerando a quem e por que se diz determinada coisa. (BRASIL, 1998, p.26)

\section{CONSIDERAÇÕES FINAIS}

Ao longo deste artigo, buscamos defender, uma prática pedagógica amparada à variação linguística, que, como vimos, já é prevista por documentos federais norteadores do ensino de língua portuguesa no Brasil. Pelas respostas do teste de crenças linguísticas, pudemos verificar a aproximação dos alunos às convenções e aos padrões institucionalizados, corroborando com outras pesquisas: há imagens e significações sobre a língua e o que "é ensinar Língua Portuguesa" que está dissociada de uma concepção de língua heterogênea, dinâmica, variável e social.

Defendemos, portanto, que para que haja um ensino que não escamoteie a diversidade linguística de seus alunos e que amplie o respeito a outras culturas e comunidades, possibilitando-lhes utilizar a modalidade oral e escrita em diferentes contextos comunicativos, de modo autônomo e eficiente, é preciso uma abordagem que privilegie a história, a identidade do sujeito e seu contexto, deixando de ser um espaço que apresente somente um ensino de regras e nomenclaturas da gramática tradicional. É preciso oportunizar atividades escolas que estejam mais próximas das práticas sociais dos alunos, pois, assim, será possível reconstruir o imaginário de padronização que está presente na sociedade e reforçado dentro de sala de aula, como observamos no teste de crenças linguísticas. 


\section{REFERÊNCIAS}

BAGNO, Marcos. Preconceito Linguístico: o que é, como se faz. São Paulo: Loyola, 2002.

BAGNO, Marcos. Preconceito Linguístico. São Paulo: Parábola, 2015.

BARBOSA, Juliana. Bertucci.; CUBA, Daiana Lombardi. Crenças e Atitudes Linguísticas de Alunos do Ensino Médio em Escolas Públicas de Uberaba. Revista Todas as Letras (MACKENZIE. Online), v. 17, p. 73-90, 2015.

BARCELOS, Ana Maria Ferreira. Crenças sobre aprendizagem de línguas, lingüística aplicada e ensino de línguas. Linguagem \& Ensino, Pelotas, v. 7, n. 1, p. 123-156, 2004.

BARCELOS, Ana Maria Ferreira. Reflexões acerca da mudança de crenças sobre ensino e aprendizagem de línguas. Rev. Brasileira de Linguística Aplicada, v. 7, n. 2, 2007.

BORTONI- RICARDO, Stella Maris. Educação em língua materna: a sociolingüística na sala de aula. São Paulo: Parábola, 2004.

BORTONI- RICARDO, Stella Maris. Nós cheguemu na escola, e agora? São Paulo: Parábola, 2005.

BRASIL. Base Nacional Comum Curricular. Disponível em: <http://basenacionalcomum. mec.gov.br/>. Acesso em: 26 ago. 2020.

BRASIL. Ministério da Educação e do desporto. Parâmetros Curriculares Nacionais de Língua Portuguesa $-3^{\circ}$ e $4^{\circ}$ ciclos. Brasília, 1998.

CAMACHO, Roberto Gomes. Sociolingüística. In: MUSSALIM, Fernanda; BENTES, Anna Cristina, (Org.). Introdução à linguística: domínios e fronteiras. 3 ed. São Paulo: Cortez, 2003. p. 49-75. v. 1.

CHAMBERS, Jack. Sociolinguistic theory: linguistic variation and its social significance. Cambridge: Basil Blackwell, 1995.

CYRANKA, Lúcia Furtado de Mendonça. Atitudes lingüísticas de alunos de escolas públicas de Juiz de Fora - mg. (Tese de doutorado). Universidade Federal Fluminense. Niterói, 2007.

DEWEY, J. How we think. Lexington, MA: D. C. Heath, 1933.

FARACO, Carlos Alberto. Norma culta brasileira: Desatando alguns nós. São Paulo: Parábola, 2008.

FARACO, Carlos Alberto. O Brasil entre a norma culta e a norma curta. In: LAGARES, Xóan; BAGNO, Marcos. Políticas da norma e conflitos linguísticos. São Paulo: Parábola, 2011. p. 49-87 
GHESSI, Rafaela Regina. Concordância verbal em português: um estudo sobre atitudes linguísticas em duas escolas públicas de Monte Azul Paulista - SP. Dissertação (Mestrado em Linguística e Língua Portuguesa) - Universidade Estadual Paulista, Araraquara, 2020.

GNERRE, Maurizio. Linguagem, escrita e poder. São Paulo: Martins Fontes, 1985.

LABOV, William. Padrões Sociolinguísticos. São Paulo: Parábola, 2008[1972].

MARCUSCHI, Luiz Antônio. Da fala para a escrita: atividades de retextualização. São Paulo: Cortez Editora, 2000.

MILROY, James. Ideologias linguísticas e as consequências da padronização. In: LAGARES, Xóan; BAGNO, Marcos. Políticas da norma e conflitos linguísticos. São Paulo: Parábola, 2011. p. 49-87

NEVES, Maria Helena de Moura. Que gramática estudar na escola? São Paulo: Contexto, 2003.

PETERMANN, Rafael, ALVES, Luiz Henrique. Língua, variação e livro didático: análise da abordagem da variação linguística em manuais didáticos do Ensino Médio. LínguaTec, Bento Gonçalves, v. 3, n. 6, p. 01-21, nov. 2018.

ROKEACH, Milton. Beliefs, attitudes, and values: A theory of organization and change. San Francisco: Jossey-Bass, 1968.

SANTOS, Emmanoel. Certo ou errado?: atitudes e crenças no ensino da língua portuguesa. Rio de Janeiro: Graphia, 1996.

SILVA, Flávio Brandão; BOTASSINI, Jacqueline Ortelan Maia. Crenças e Atitudes Linguísticas: o que pensam os alunos de Letras sobre o ensino de Língua Portuguesa. Letras \& Letras, Uberlândia, vol. 31/2, jul/dez, 2015.

WEINREICH, Uriel; LABOV, William; HERZOG, Marvin. Fundamentos empíricos para uma teoria da mudança linguística. Tradução Marcos Bagno. São Paulo: Parábola Editorial, 2006.

YERO, Judith Lloyd. Teaching in mind: how teacher thinking shapes education. 2 nd ed. Hamilton, MT: Mind Flight Publishing, 2010.

RECEBIDO EM: 29/01/2021

ACEITE EM: 07/06/2021 